\title{
Collateral damage of COVID-19-lockdown in Germany: decline of NSTE-ACS admissions
}

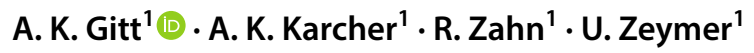

Received: 4 May 2020 / Accepted: 1 July 2020 / Published online: 10 July 2020

(c) Springer-Verlag GmbH Germany, part of Springer Nature 2020

Sirs:

The SARS-CoV-2-Pandemic reaching Germany in March 2020 led to a nation-wide lockdown with serious restrictions on public life. Based on the experiences of the tsunami-like waves of infections in other European countries, Germany was preparing for a massive load of severe COVID-19-cases by increasing the number of intensive-care-beds and by cancelling the majority of elective medical procedures to provide as many hospital beds as possible.

We conducted a retrospective review of ACS-admissions to the Heart Center Ludwigshafen, an academic tertiary heart center in Germany (using ICD-codes I20.0; I21.0, I21.1 and I21.4). We compared the period March 1st to April 21st in 2020 with the same time period in the years 2017-2019 as reference. We did the same analysis for January and February 2017-2020 to show average numbers of ACS cases over the years.

During the COVID-19 lockdown in Germany in March/ April 2020, we observed unchanged numbers for STEMIadmissions, but a significant 50\% reduction in NSTE-ACS, in both UA and NSTEMI (Fig. 1). Similar findings were previously reported in Austria and Italy [1, 2].

We compared patient characteristics of ACS patients during the COVID-lockdown with the same time period of the year 2019 (Table 1). We did not find any relevant differences in the patient characteristics during the COVID-lockdown as compared to the year before. The current data do not provide any indication of who of the ACS population was not admitted to the hospital during the COVID-lockdown. We provide data on troponin values of all NSTEMI patients for the two time periods in 2019 and 2020 in the table. The troponin values reported are the maximal values on the first 2 days after admission for the acute event. The median troponin values during the COVID-lockdown were slightly higher as compared to the values from 2019, but significance was not reached (Table 1).

Possible explanations for this important observation might be system-related as well as patient-related. By concentrating on the preparation for the COVID-19-pandemic with all necessary efforts undertaken to care for the isolation and treatment of suspected or confirmed cases, established integrated care systems for other acute diseases with well-defined patient pathways might have been neglected. Besides, the lockdown isolated many patients at risk for cardiovascular events and the quarantine of patients with suspected or confirmed SARS-CoV-2-infection at home sometimes might have prevented them from contacting their doctors. The acute presentation of STEMI with severe chestpain probably still triggers the direct transportation to the cathlabs with no changes of admissions. Due to the attention to the plethora of possible symptoms of the SARS-CoV2-infection described in the media, some patients may have mis-interpreted their NSTE-ACS symptoms such as dyspnea and chest pain as possible COVID-19-symptoms rather than as cardiovascular symptoms. As an early invasive treatment of NSTEMI-patients is associated with an improved outcome [3,4], we might face a higher mortality by non-treated ACS patients as a collateral damage of the COVID-19-era.

We, therefore, should take care about reinforcing the already established patient pathways ensuring the access to emergency cardiology care of those patients separated from the access to hospital care for COVID-19-infections that will continue to accompany us in the future until an effective vaccine is developed, to avoid undertreatment of NSTE-ACS-patients.

A. K. Gitt

gitta@klilu.de

1 Med. Klinik B, Department of Cardiology, Herzzentrum Ludwigshafen, Ludwigshafen, Germany 
Table 1 Patient characteristics of ACS patients (STEMI, NSTEMI, UA) for the time periods March, 1 to April, 212019 compared to March, 1 to April, 212020

\begin{tabular}{|c|c|c|c|c|c|c|c|c|c|}
\hline & STEMI & & & NSTEMI & & & UA & & \\
\hline Time period & Mar-Apr 2019 & Mar-Apr 2020 & $p$ value & Mar-Apr 2019 & Mar-Apr 2020 & $p$ value & Mar-Apr 2019 & Mar-Apr 2020 & $p$ value \\
\hline $\begin{array}{l}\text { Number of } \\
\text { admissions } \\
(n)\end{array}$ & 49 & 46 & n.s & 95 & 50 & $<0.001$ & 94 & 48 & $<0.001$ \\
\hline $\begin{array}{l}\text { Female } \\
\text { gender }\end{array}$ & $26.5 \%(13 / 49)$ & $32.6 \%(15 / 46)$ & 0.52 & $27.4 \%(26 / 95)$ & $32.0 \%(16 / 50)$ & 0.56 & $38.3 \%(36 / 94)$ & $43.8 \%(21 / 48)$ & 0.53 \\
\hline $\begin{array}{l}\text { Age (years. } \\
\text { mean } \pm \text { SD) }\end{array}$ & $65,9 \pm 14,2$ & $64,0 \pm 13,8$ & 0.67 & $70,5 \pm 12,3$ & $71,7 \pm 12,1$ & 0.58 & $68.8 \pm 13.7$ & $70.5 \pm 10.8$ & 0.58 \\
\hline \multicolumn{10}{|l|}{$\mathrm{CV}$ risk factors } \\
\hline $\begin{array}{l}\text { Art. hyperten- } \\
\text { sion }\end{array}$ & $83.7 \%(41 / 49)$ & $73.9 \%(34 / 46)$ & 0.24 & $77.9 \%(74 / 95)$ & $82.0 \%(41 / 50)$ & 0.56 & $83.0 \%(78 / 94)$ & $83.3 \%(40 / 48)$ & 0.96 \\
\hline $\begin{array}{l}\text { Diabetes mel- } \\
\text { litus }\end{array}$ & $16.3 \%(8 / 49)$ & $34.8 \%(16 / 46)$ & $<0.05$ & $33.7 \%(32 / 95)$ & $40.0 \%(20 / 50)$ & 0.45 & $29.8 \%(28 / 94)$ & $20.8 \%(10 / 48)$ & 0.25 \\
\hline $\begin{array}{l}\text { Hyperlipi- } \\
\text { demia }\end{array}$ & $51.0 \%(25 / 49)$ & $65.2 \%(30 / 46)$ & 0.16 & $61.1 \%(58 / 95)$ & $74.0 \%(37 / 50)$ & 0.12 & $45.7 \%(43 / 94)$ & $66.7 \%(32 / 48)$ & $<0.05$ \\
\hline $\begin{array}{l}\text { Smoker (cur- } \\
\text { rent) }\end{array}$ & $22.4 \%(11 / 49)$ & $15.2 \%(7 / 46)$ & 0.37 & $9.5 \%(9 / 95)$ & $6.0 \%(3 / 50)$ & 0.47 & $7.4 \%(7 / 94)$ & $10.4 \%(5 / 48)$ & 0.55 \\
\hline Comorbidities & $6.1 \%(3 / 49)$ & $2.2 \%(1 / 46)$ & 0.34 & $9.5 \%(9 / 95)$ & $6.0 \%(3 / 50)$ & 0.47 & $10.6 \%(10 / 94)$ & $12.5 \%(6 / 48)$ & 0.74 \\
\hline COPD & $0.0 \%(0 / 49)$ & $2.2 \%(1 / 46)$ & 0.30 & $17.9 \%(17 / 95)$ & $14.0 \%(7 / 50)$ & 0.55 & $6.4 \%(6 / 94)$ & $4.2 \%(2 / 48)$ & 0.59 \\
\hline $\begin{array}{l}\text { Peripheral } \\
\text { artery } \\
\text { disease }\end{array}$ & $2.0 \%(1 / 49)$ & $0.0 \%(0 / 46)$ & 0.33 & $1.1 \%(1 / 95)$ & $2.0 \%(1 / 50)$ & 0.64 & $0.0 \%(0 / 94)$ & $0.0 \%(0 / 48)$ & n.a \\
\hline $\begin{array}{l}\text { Prior stroke/ } \\
\text { TIA }\end{array}$ & $16.3 \%(8 / 49)$ & $13.0 \%(6 / 46)$ & 0.65 & $42.1 \%(40 / 95)$ & $36.0 \%(18 / 50)$ & 0.48 & $20.2 \%(19 / 94)$ & $18.8 \%(9 / 48)$ & 0.84 \\
\hline Renal failure & $6.1 \%(3 / 49)$ & $2.2 \%(1 / 46)$ & 0.34 & $9.5 \%(9 / 95)$ & $6.0 \%(3 / 50)$ & 0.47 & $10.6 \%(10 / 94)$ & $12.5 \%(6 / 48)$ & 0.74 \\
\hline $\begin{array}{l}\text { Troponin I } \\
\text { hs (ng/l) } \\
\text { Median with } \\
\text { interquartile } \\
\text { range }\end{array}$ & n.a & n.a & n.a & $\begin{array}{c}1179,0(294,0 ; \\
5660,0)\end{array}$ & $\begin{array}{l}1501,0(530,0 \\
8788,0)\end{array}$ & 0.27 & $\mathrm{n} . \mathrm{a}$ & n.a & n.a \\
\hline
\end{tabular}

STEMI ST-elevation-myocardial-infarction, NSTEMI Non-ST-elevation-myocardial-infarction, UA unstable angina

Statistical Analysis: Continuous variables are presented as mean with standard deviation or median with interquartile range and compared with Mann-Whitney-Wilcoxon test. Categorical variables are presented as counts and percentages and compared with the Chi ${ }^{2}$-test. All tests were two-tailed and $p$ values $<0.05$ were considered statistically significant. Statistical analyses were performed with SAS statistical package, version 9.4 (SAS Institute)

A. ACS-Admissions Jan-Feb 2017-2020

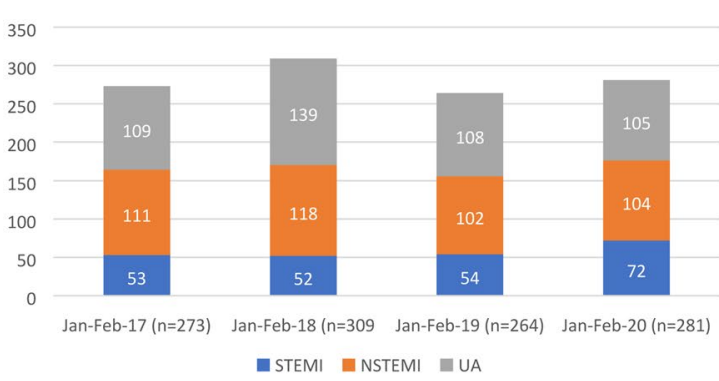

Fig. 1 ACS admissions to an academic tertiary heart center before and during the shut-down for the SARS-COV-2-pandemic in Germany. Panel a: Number of treated patients with STEMI, NSTEMI and UA for the periods of January and February 2017 to 2020: Numbers are stable over 4 years. Panel b: Number of treated patients with
B. ACS-Admissions Mar-Apr 2017-2020

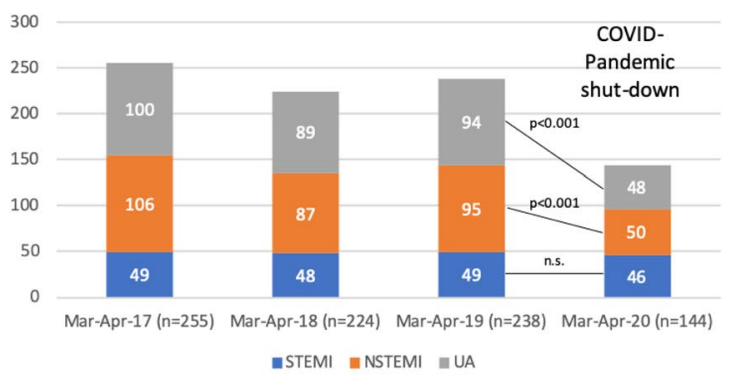

STEMI, NSTEMI and UA for the periods of March and April (until April 21st) 2017 to 2020: Numbers of NSTEMI and UA drop by $50 \%$ in 2020. STEMI ST-elevation-myocardial-infarction, NSTEMI NonST-elevation-myocardial-infarction, $U A$ unstable angina 


\section{References}

1. Metzler B, Siostrzonek P, Binder RK, Bauer A, Reinstadler SJ (2020) Decline of acute coronary syndrome admissions in Austria since the outbreak of COVID-19: the pandemic response causes cardiac collateral damage. Eur Heart J 41(19):1852-1853

2. De Filippo O, D’Ascenzo F, Angelini F, Bocchino PP, Conrotto F, Saglietto A (2020) Reduced rate of hospital admissions for ACS during Covid-19 outbreak in Northern Italy. N Engl J Med 383:88-89

3. Fox KA, Clayton TC, Damman P, Pocock SJ, de Winter RJ, Tijssen JG, Lagerqvist B, Wallentin L (2010) Long-term outcome of a routine versus selective invasive strategy in patients with nonST-segment elevation acute coronary syndrome a meta-analysis of individual patient data. J Am Coll Cardiol 55:2435-2445

4. Navarese EP, Gurbel PA, Andreotti F, Tantry U, Jeong YH, Kozinski M, Engstrom T, Di Pasquale G, Kochman W, Ardissino D, Kedhi E, Stone GW, Kubica J (2013) Optimal timing of coronary invasive strategy in non-ST-segment eleva- tion acute coronary syndromes: a systematic review and meta-analysis. Ann Intern Med 158:261-270 